BNL 51126

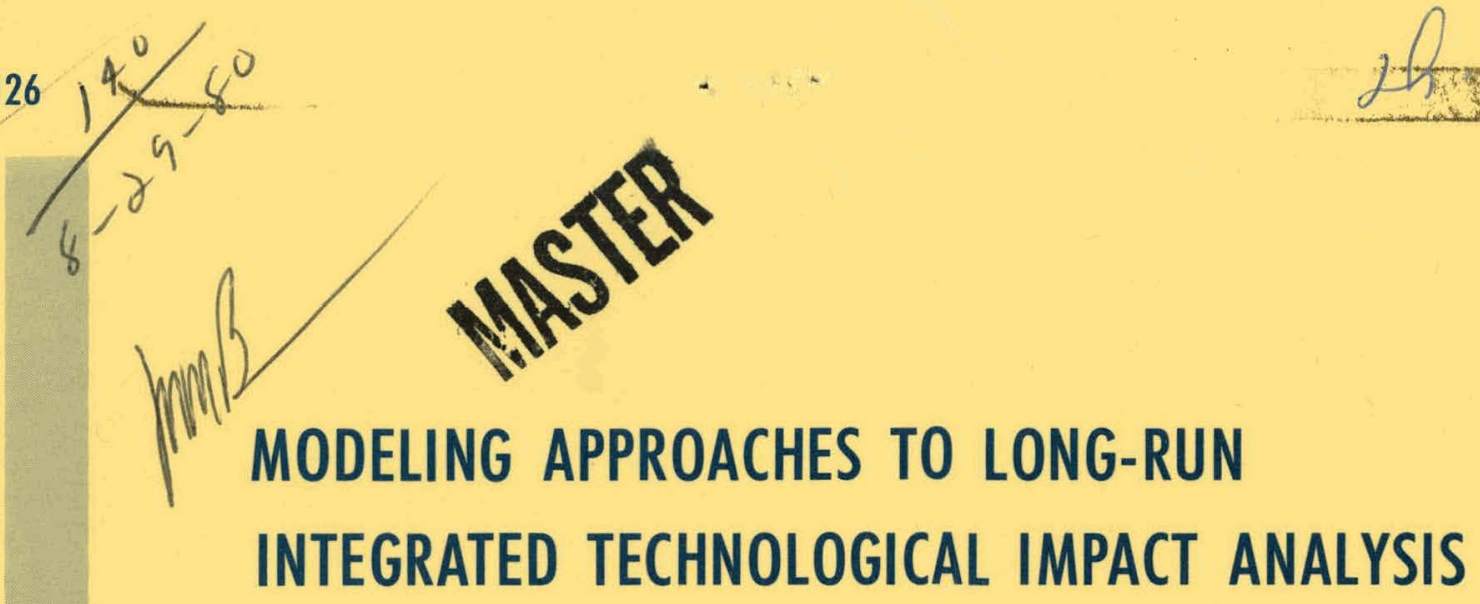

PAUL J. GRONCKI

December 1979

DEPARTMENT OF ENERGY AND ENVIRONMENT

BROOKHAVEN NATIONAL LABORATORY UPTON, NEW YORK 11973 


\section{DISCLAIMER}

This report was prepared as an account of work sponsored by an agency of the United States Government. Neither the United States Government nor any agency Thereof, nor any of their employees, makes any warranty, express or implied, or assumes any legal liability or responsibility for the accuracy, completeness, or usefulness of any information, apparatus, product, or process disclosed, or represents that its use would not infringe privately owned rights. Reference herein to any specific commercial product, process, or service by trade name, trademark, manufacturer, or otherwise does not necessarily constitute or imply its endorsement, recommendation, or favoring by the United States Government or any agency thereof. The views and opinions of authors expressed herein do not necessarily state or reflect those of the United States Government or any agency thereof. 


\section{DISCLAIMER}

Portions of this document may be illegible in electronic image products. Images are produced from the best available original document. 


\title{
MODELING APPROACHES TO LONG-RUN INTEGRATED TECHNOLOGICAL IMPACT ANALYSIS
}

\author{
PAUL J. Groncki
}

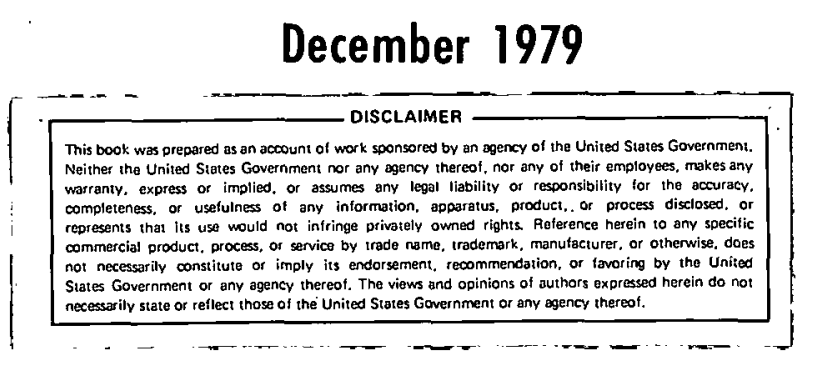

ECONOMIC ANALYSIS DIVISION

\section{NATIONAL CENTER FOR ANALYSIS OF ENERGY SYSTEMS DEPARTMENT OF ENERGY AND ENVIRONMENT BROOKHAVEN NATIONAL LABORATORY ASSOCIATED UNIVERSITIES, INC.}

UNDER CONTRACT NO. DE-AC02-76CH00016 WITH THE UNITED STATES DEPARTMENT OF ENERGY 


\section{DISCLAIMER}

This book was prepared as an account of work sponsored by an agenry nf the IInited States Government. Neither the United States Government nor any agency thereof, nor any of their employees, makes any warranty, express or implied, or assumes any legal liability or responsibility for the accuracy, completeness, or uscfulness of any information, apparatus, product, or process disclosed, or represents that its use would

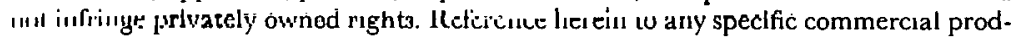
uct, process, or service by trade name, trademark, manufacturer, or otherwise, does not necessarily constitutc or imply its endursement, recommendation, or favoring by the United States Government or any agency thereof. The views and opinions of authors expressed herein do not necessarily state or reflect those of the Unitcd States Government or any agency thereof.

Printed in the United States of America Available from

National Technical Information Service

U.S. Department of Commerce

5285 Port Royal Road

Springfield, VA 22161

Price: Printed Copy $\$ 4.00$; Microfiche $\$ 3.00$ 


\begin{abstract}
Analysis of the energy-economic-environmental impacts of energy policies, such as a major synthetic fuels program, requires methodologies that reflect the potential benefits and costs of proposed policy alternatives. Energy policies typically have secondary economic and environmental effects as well as direct effects on energy itself, and these must collectively be assessed to provide a complete basis for policy selection. The focus of this report is on approaches to the analysis of longterm impacts that may result from current decisions regarding energy policy. The interrelationships among the energy, economic, and environmental systems, and alternative ways of analyzing long-term impacts within an integrated framework are discussed. An application of such a framework to the assessment of a major synthetic fuels program is presented as an example.

The use of idealized problem formulations is a necessary part of technology assessment, particularly in considering highly integrated policy issues, such as a synfuels policy. Nonquantifiable factors; such as equity, are not always considered in mathematical models. Model results should be viewed only as aids for decisionmaking among policy alternatives, as they may not take into account all of the policy's implications. A decisionmaker must recognize the limitations to using model outputs and must use both experience and judgment in selecting policy alternatives for implementation. Use of an appropriate model structure with sufficient feedback capabilities will often provide a better overall policy assessment than a highly detailed but uncoordinated approach to the same problems.
\end{abstract}

\title{
ACKNOWLEDGEMENT
}

This paper synthesizes the efforts of several other people on a variety of projects. In particular, I would like to thank Peter Kleeman and Joan Lukachinski for their contributions and comments. 


\section{THIS PAGE}

\section{WAS INTENTIONALLY LEFT BLANK}


Abstract $\ldots \ldots \ldots \ldots \ldots \ldots \ldots \ldots \ldots \ldots \ldots \ldots \ldots \ldots \ldots \ldots \ldots \ldots \ldots \ldots \ldots$

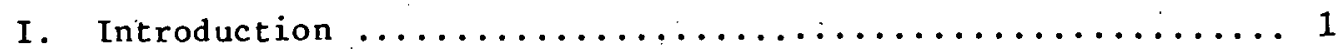

II. Estimation of Policy Impacts Over Time .............. 2

III. Energy, Economic, and Environmental Interactions ........4

IV. Methodologies for Energy-Economic-Environmental

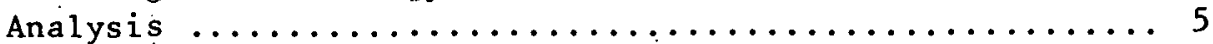

V. Future Development Needs for Integrated Modeling ....... 6

VI. Model Representations of Long-Term Policies .......... 8

VII. Environmental Analysis in an Integrated Framework ........9

VII A. An Application of An Integrated Modeling Approach

to Synthetic Fuels Policy ..................... 9

VIII.1 Study Assumption and Methods ...............11

VIII.2 Reference Case Assumption .................12

VI.I. 3 Energy Assumptions-Synfuels Case .............13

VIII.4 Comparison of Reference and Synfuels Policy ...... 14

VIII.5 Policy Implications ...................16

IX Conclusion $\ldots \ldots \ldots \ldots \ldots \ldots \ldots \ldots \ldots \ldots \ldots \ldots$

References $\ldots \ldots \ldots \ldots \ldots \ldots \ldots \ldots \ldots \ldots \ldots \ldots \ldots \ldots \ldots \ldots \ldots \ldots \ldots$ 
Summary of Energy, Economy, and Environmental

Effects of Energy Policies ................... 10

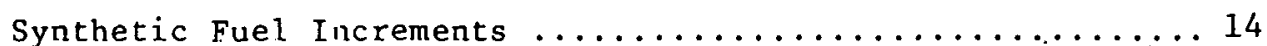

Synthetic Euel Cost Assumptions ................ 15

4 Comparison of Cases, Economic. Summary in $10^{9}$ (1972) ..... 15

5 Comparison of Cases, Annual Energy Quantities

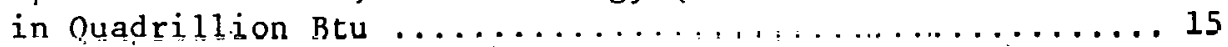

6 Comparison of Cases, Environmental Measures .......... 16

\section{FIGURES}

1 Schematic of energy, economic, and environmental interactions $\ldots \ldots \ldots \ldots \ldots \ldots \ldots \ldots \ldots \ldots \ldots \ldots \ldots \ldots$

2 Schematic of fully integrated energy-economyenvironmental systems modeling $\ldots \ldots \ldots \ldots \ldots \ldots$

3 Schematic of the current state of the art in energyecumunic-envirummencal sysceñs mồèling $\ldots \ldots \ldots \ldots \ldots \ldots$

4 Hypothetical projections from short-run and long-run models ........................ 8 


\section{INTRODUCTION}

An analysis of the energy-economic-environmental impacts of energy policies, such as a major synthetic fuels program, requires the use of methodologies that reflect the potential benefits and costs of proposed policy alternatives. Energy policies typically have secondary economic and enviromental effects as well as direct effects on energy itself, and these must collectively be assessed to provide a complete basis for po1icy selection. Some energy policies may result in the generation of environmental residuals which produce only short-run environmental impacts, while others may generate residuals with long half-lives and impacts that will be felt for many decades. Some policies produce the residuals now, while others produce them later. Thus, complete assessment of environmental impacts must include not only levels but timing of impacts. Similarly, different policies could lead to different levels and time schedules for synthetic fuels implementation. In addition, it is necessary to include interactions among energy, economic, and environmental subsystems which may affect the quality of the environmental impact estimates as well as estimates of economic and energy-related activities over time.

This paper is primarily concerned with approaches to the analysis of long-term impacts that may result from current decisions regarding energy policy. The interrelationships among the energy, economic, and environmental systems, and alternative ways of analyzing long-term impacts within an integrated framework are discussed. Much of this discussion is drawn from a report produced for the Division of Environmental Impacts, U.S. Department of Energy. 1 An application of such a framework to the assessment of a major synfuels program is presented as an example. ${ }^{2}$

Use of an integrated framework has great appeal for policy analysis.

In the past few decades, analysts have pointed out the need for multidisciplinary approaches to problems previously treated independently. Increased awareness of the impacts of economic activity on environmental quality has led to legislation requiring environmental and other impact assessments for a wide variety of economic development projects.

Structuring a framework in which to carry out integrated analysis with environmental impact analysis as only one of several components requires so highly detailed a system that its use in policy analysis would be impractical if not impossible. Thus, an integrated model formulation must often rely ui indicalors of system behavior rather than estimated impacts as a basis for policy assessment. One useful indicator of environmental impact is a vector of residual emission quantities. Elements of this vector can be compared across policies to provide an aggregated measure of relative impacts. Corresponding indicators for the economic and energy components may include GNP and quantity of primary energy consumed, respectively.

A measure of effectiveness by which each policy alternative can be assessed must be consistent with the overall level of detail within each component of the integrated system. This measure of effectiveness may take the form of an objective function value with energy, econonic, and 
environmental terms included. ${ }^{3}$ Ultimate policy selection may then be based upon the differences in objective function values between policies. Single-objective. analyses, however, require that all components in the objective function be of commensurate units (e.g., dollars) which requires that indicators of economic activity and residual emissions be converted to a common unit. ${ }^{4}$ This is often impossible, and a multiobjective analysis may be an acceptable alternative. This alternative approach to policy assessment eliminates the need for commensurate units but requires that weights or preferences be attached to each objective so that a policy which best satisfies a weighted function of the objectives can be identified. 5,6 In either case, the measure of policy alternatives should be chosen to assist in selecting a desirable policy for implementation. In selecting indicators of long-term policy effectiveness, appropriate evaluation of alternatives may require indicators of cumulative residuals, or cumulative GNP foregone, as concrasted will ineasures of single-period activity levels.

The range of policy issues which can be analyzed using an integrated modeling framework far exceeds the capabilities of nonintegrated methodolopies. Through selection of appropriate ohjectives and measures of effectiveness, policy issues concerning tradeoffs between tirergy consumption, economic growth, and environmental impacts can be assessed with greater reliability.

The estimation of technological impacts over time for purposes of policy analysis is presented in section II. In section III of this report we discuss the interrelationship among the energy, economic and environmental subsystems, and their consequences for policy analysis. In Sections. IV and $V$ we examine the difficulties associated with bridging the gap between current nodel capabilities and the type of modeling, capabilities necessary for fully integrated analyses. Major areas needing future development are given in Section V. In Section VI we address the problem of linking results from short-run detailed and long-run aggregated models into projections over long-run time horizons. In Section VIT we address specific environmental analysis issues and how they can be handled in an integrated framework. Sectiuu vili deseribco an application of such an. integrated approach to the analysis of a major synthetic fuels program.

\section{ESTIMATION OF POLICY IMPACTS OVER TIME}

Policy impacts over a time horizon of $T$ years can be represented in a variety of ways. The ideal reprecentation wnuld be a continuous function of an impact measure over the entire time horizon of $T$ years. Analytical effort and quality of information required to generate such functinns are generally too great for all but a few policy cases. A set of point estimates of policy impacts can be used as a surrogate for a coitinuous impact function for purposes of policy assessment. Each of these point estimates can reflect the impact at a time $\mathrm{N}$ years into the time horizon, as defined below.

Let

$$
\begin{aligned}
& T_{0}=\text { time at which policy decision } 0 \text { is made, } \\
& T_{N}=\text { time at which impact of } O \text { is to be estimated, }
\end{aligned}
$$




$$
\begin{aligned}
A_{i} & =\text { activity in } T_{i} \text { which may produce impacts in } T_{j} \text { for } T_{j}>T_{i}, \\
I_{j} & =\text { estimated value of impact measure in } T_{j}, \\
a_{i j} & =\text { coefficient relating activity level in } T_{i} \text { to impacts in } \\
& T_{j} \text {. }
\end{aligned}
$$

Using these definitions, the $N^{t h}$-year impact, $I_{N}$, can be computed

$$
I_{N}=\sum_{i=0}^{N} a_{i N} A_{i}
$$

Estimates of $I_{N}$ for alternative policies can be compared to assess the relative impacts of different policies at several points in the time horizon. Selection of an impact measure itself for comparison is critical in policy impact assessment. Environmental effects, ambient environmental quality, level of residuals emission, GNP, employment, total energy use, coal use, imports, or other indicators can be chosen for the $\mathrm{N}^{\text {th }}$-year impact measure. Different impact indicators may be desirable for different policy assessments. Some of the issues of indicator selection are described below.

Nature of the policy under consideration. Policy focus may determine the selection of an impact indicator. Selection of environmental effects for comparison across alternatives would under all circumstances be most desirable if analytical resources were unlimited. But, surrogate measures such as emission levels may be suitable for policy assessment. Policies affecting levels of highly toxic waste production, for example, may be compared using residual levels which may contain sufficient information for policy assessment without requiring estimation of the environmental impacts these levels produce.

Quality of methods (models) available for estimating impact parameters. Functional relationships between residuals and their impacts often require a large number of parameters for specification. Environmental effects are a function of ambient quality, rates of residual emission, chemical activity between residuals and the environment during transport, location of sensitive receptors, and a variety of other residual-dependent parameters. For a wide range of policy issues, the production of environmental impact estimates under the high degree of uncertainty of functional parameters may not provide significantly better information than other indicators.

Proportion of total impact in year $T_{N}$. The marginal energy-economic-environmental effects produced as a result of a policy $?$ in $T_{N}$ is therefore dependent upon other policies which may be implemented in the period $\left[T_{0}, T_{N}\right]$. If the impact associated with $Q$ dominates impacts from these other policies, then ignoring these other policy effects may be reasonable. However, if the impacts of $Q$ are relatively small compared to the other policies, it may be difficult to assess the relative impacts among these policy alternatives.

Length of time horizon. Uncertainty about all of the paramelers required to estimate the effects of energy or any otner policy decision increases with $N$. Energy-economic-environmental effects may be computed 
with significantly greater reliability for short time horizons than for long time horizons.

A 'best' impact measure for particular policy assessment may not be readily identifiable based on the issues above. In such cases an efficiency notion can be employed for selection. The primary goal in computing an impact measure is to distinguish among alternative policies as to their relative benefits and costs. An efficient impact measure could be defined as that which best balances benefits of information against the costs of providing (computing) information. Such a ranking of measures by their efficiencies would end in the selection of the appropriate measure for distinguishing among specific policy alternatives.

\section{ENERGY, ECONOMTC, AND ENVIRONMENTAL INTERACTIONS}

The interactions among energy, economic, and environmental considerations are presented schematically in Figure 1. Here, the three circles represent energy, economic, and environmental issues, and the areas 1 abcled, A, B, C, and D the interactions among them. In a modeling context each circle can be viewed as the set of model variables associated with each subsystem. The intersections of these sets then contain the variables which reflect interaction among these subsystems.

Policies affecting energy management will generally fall into the area labeled D. Examples of interactions between energy policy and environmental quality or national economy are not difficult to identify. The impact of a policy to impose foreign oil import quotas, or to estab1 ish a large synfuels industry, for example, has implications in both the economic and environmental subsystems. Some energy policy issues may adequately be assessed by considering only the energy-economy ( $B$ ) or energy-environment (A) interactions.

Two important steps in policy assessment are to identify relevant interactions, and then reflect these interactions in the assessment. If important interactions among subsystems are omitted, there may be 1 arge distortions in measuring benefits and costo accociated with a plicy. For example, where total system cost is the measurc uced to compare the

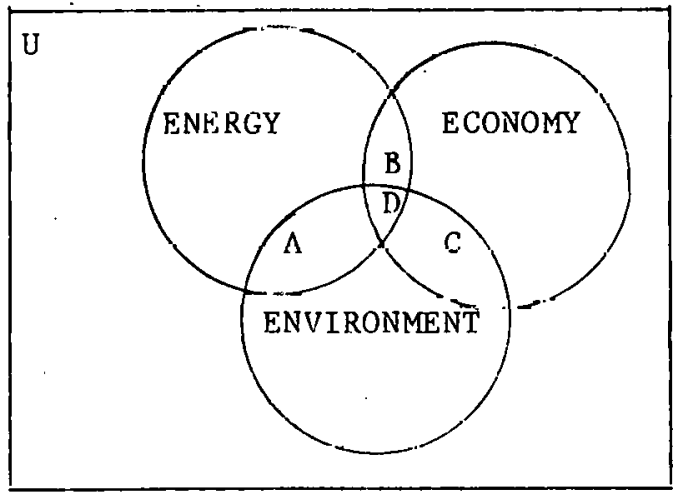

Figure 1. Schematic of energy, economic, and environmental interactions. 
effectiveness of alternative policies, omission of environmental guidelines or constraints will permit an energy policy to have a lower total system cost than the integrated energy-environmental system. Such a distorted assessuent may then favor selection of the policy with the greatest impact on subsystems not adequately integrated into the assessment model.

The key issue here is the extent to which interactions are represented. This certainly depends upon a variety of considerations, including :

- nature of policies being assessed,

- quality of available data,

- quality of models used in assessment,

- level of detail required to distinguish between policy alternatives,

- cost effectiveness of generating information.

The objective of modeling is to approximate behavior of a complex system with a tractable representation useful for analysis. There are no prescribed methods for defining an appropriate level of interaction between subsystems. Only through understanding of the system under consideration and the issues given above can an appropriate level of interaction and detail be specified.

With very extensive resources, highly integrated systems might possibly be specified, and highly detailed policy assessments made. Unfortunately resources are limited and the level of resources available for analyzing policy options must also be considered in choosing a model structure for the analysis.

\section{METHODOLOGIES FOR ENERGY-ECONOMIC-ENVIRONMENTAL ANALYSIS}

National policy analysis requires use of a comprehensive model framework that can trace effects of alternative national economic and energy policy parameters on regional energy use patterns and economic activity. The model system must include component models of the energy system, the economy, and the environment specified at several levels of regional aggregation. Linkage of a macroeconomic growth model to a national cnergy systems mudel can be used to generate levels of aggregate economic activity and energy production and consumption patterns consistent with an exogenously specified set of resource prices and constraints on availabilities of factors of production. A flexible coefficient input-output model can be aligned to an initial aggregate energy-economic solution to yield economic activity by sector. Regionalization of these activity levels can be achieved by using a regional model that disaggregates national activity levels while maintaining energy supply and demand balances within each region, or through alignment of a set of regionalspecific input-output models to the national totals. Information must be disaggregated in order to obtain levels of environmental impacts by source and typc of emission. Regional activity levels by sector may be sufficiently disaggregated to allow for measurement of certain environmental effects, but most environmental impacts must be determined from 
local levels of process activity. In order to analyze system effects of environmental regulations and introduction of abatement technologies, a critical component of the overall model framework is an interface between environmental and economic model components. This linkage would allow feedback of emission control constraints in terms of changes in production functions, resource and capital costs, and factor productivities on the aggregate level of economic activity. By including this economyenvironment interface, each of the energy, economic, and environmental components of the overall modeling system will be integrated with the other two. Linkage between the energy and environmental model components is only considered in one direction while the link between the economic and environmental components is often poorly specified, if at all.

\section{FUTURE DEVELOPMENT NEEDS FOR INTEGRATED MODELING}

The primary components of integrated energy-economic-environmental modeling systems in need of development are the links between environmental and economic and envirumueulal and energy subayuteme. These links correspond to the arrows in Figure 2 but not to those in Figure 3 . A schematic diagram of a fully integrated system is shown in Figure 2.

The arrows connecting each subsystem represent a linkage mechanism which must allow each subsystem to be influenced by the constraints of the other. Arrows are given for directional linkages since each sector of a connected pair should be able to influence the behavior of the other.

A schematic diagram of the current state of the art in energy-economic-environmental modeling is shown in Figure 3 .

General forms for equations to link the environmental and economic subsystems, for example, can be specified, but the information required to adequately specify linkage equation coefficients is not available. As a result, exogenous calculations must be performed on model results to estimate some economic impacts of environmental policies. Since the two

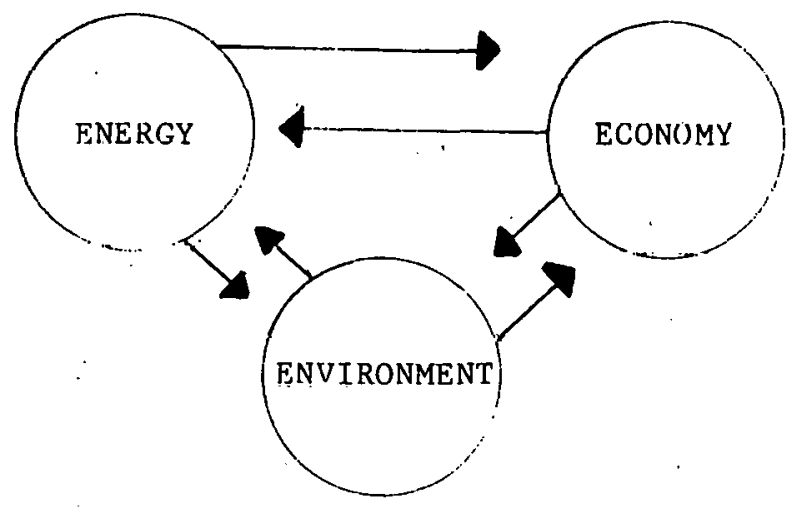

Figure 2. Schematic of fully integrated energy-economyenvironmental systems modeling. 


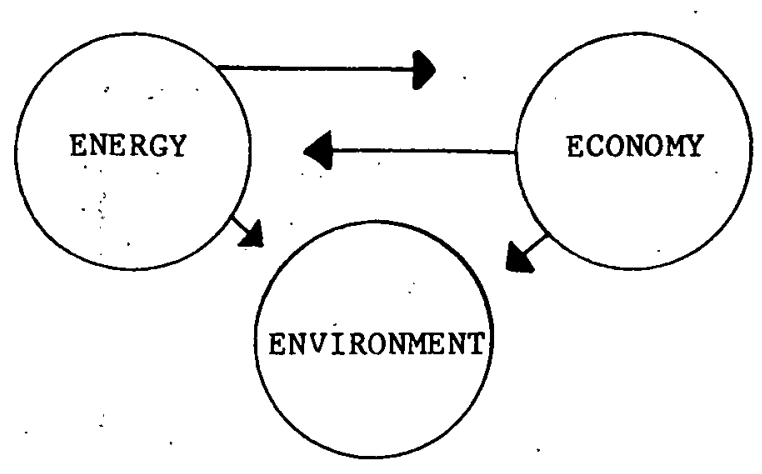

Figure 3. Schematic of the current state of the art in energy-economic-environmental systems modeling.

General forms for equations to link the environmental and economic subsystems, for example, can be specified, but the information required to adequately specify linkage equation coefficients is not available. As a result, exogenous calculations must be performed on model results to estimate some economic impacts of environmental policies. Since the two subsystems are not truly integrated, these issues are not easily analyzed and errors in policy assessment may become significant.

In the environment-energy linkage, for example, increasingly stringent environmental constraints (regulations) will impose costs on the economy. First-order or direct costs of pollution-abatement equipment necessary to meet these constraints are often used as indicators of all economic costs since the nature and magnitude of total economic costs are not well understood. Development of these linkages must include specification of mathematical equations to feedback these or other costs generated because of environmental considerations into the economic and energy subsystems within an integrated model framework. This information may be most necessary to handle secondary impacts since primary impacts $c$ an be more readily handled without integration.

In addition to subsystem linkage development needs, further development within each subsystem should also be undertaken. Improvements within a single component will not unly improve the understanding of the impacts of alternative policy in that subsystem, but al so the quality of information used to assess the indirect impacts in the other subsystems. These improvements do not necessarily require greater modeling detail, especially when the components are to be integrated into a larger modeling system. In fact, the desired level of detail for each component of an integrated system will generally be lower than for independent models since highly detailed integrated models may be difficult to specify and calibrate, and often become computationally unwieldy. 


\section{MODEL REPRESENTATIONS OF LONG-TERM POLICIES}

Level of detail required for analysis also depends upon the length of time horizon specified. Increasing uncertainty about system constraints in the future make aggregated models increasingly more appropriate for policy analysis. Often, analysis of policy alternatives requires a detailed examination of immediate short-term costs and benefits as well as long-term projected energy and economic activity. Linkage of a detailed short-term system model with a long-run more aggregated model could provide information needed for policy evaluation. The two model systems could be aligned in terms of data and integrating variables. The aggregated long-run model could determine the general equilibrium growth path for the system solution but might not capture short-term constraints alud cyclical econnmic behavior. The short-term model could be used to determine a detailed description of near-term impacts of long-run policies. Because of different dynamics in the short- and long-run solutions, transition year $\left(Y_{t}\right)$ projections generated by each model may not be consistent, as shown in Figure 4.

For a variety of policy questions the output functions for a shortrun model and a long-run model may be combined into one functional description of system behavior. Since a short-run model will capture more. system detail than the long-run model, it may exhibit much more erratic behavior than the long-run model. But, if the function is smoothed (output data are aggregated), a function more similar to the form of the

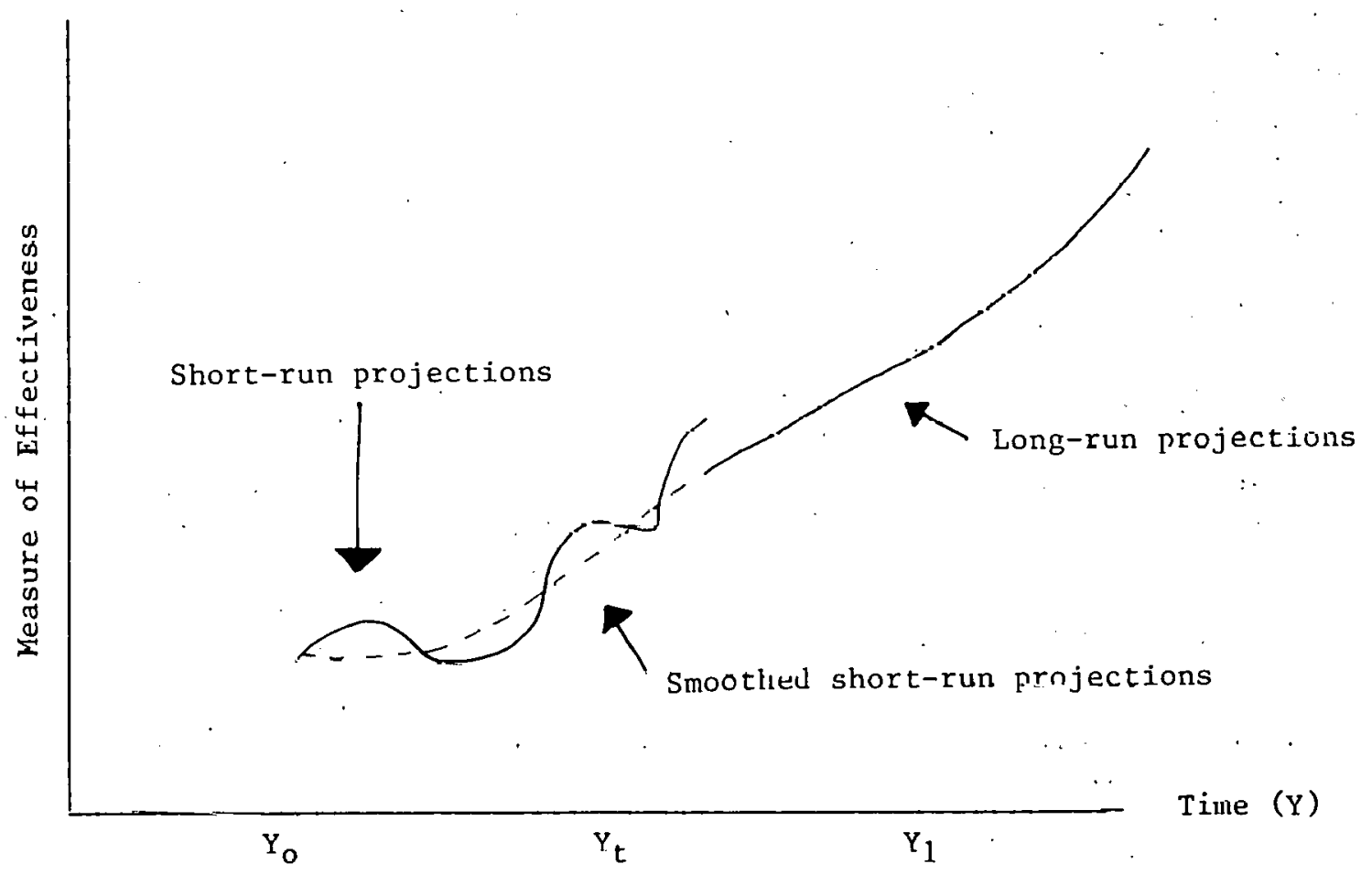

Figure 4. Hypothetical projections from short-run and long-run models. 
long-run function should be identified. When these functions are within an acceptable tolerance of each other, a function formed from both shortrun and long-run projections can be constructed. If the smoothed shortrun function is not within the specified tolerance of the long-run function, a single projection may misrepresent the available information.

Figure 4 also indicates a schematic of how functional projections can be combined when smoothed short-run and long-run model functions between $Y_{o}$ and $Y_{t}$ are comparable. The discontinuity between short-run and long-run results at the end of the short-run time horizon, $Y_{t}$, implies that some care should be exercised in interpreting results within a neighborhood of $Y_{t}$. Many policy analyses may not require smoothing since long-run and short-run model results from each policy alternative can be compared independently: e.g., when relative costs or benefits are being compared and smooth projections provide no additional information about the policy alternatives.

\section{ENVIRONMENTAL ANALYSIS IN AN INTEGRATED FRAMEWORK}

As noted in Figure 3, environmental impact calculations are primarily done as "end-of-run" computations in current integrated modeling systems. Integrated energy and economic output vectors are generally multiplied by a vector of environmental effects coefficients to generate indicators of aggregated impacts for a variety of environmental issues. Use of current methodologies for evaluating environmental impacts is not appropriate unless the linkages between environmental and energy, and environmental and economic subsystems can be specified as constraints upon an integrated energy-economy model. This situation exists when environmental emission regulations are being assessed. Model objective functions which can be evaluated for this case can only include energy and economic variables, however, as all the environmental considerations enter as constraints on the total system.

Analysis of environmental policy for issues other than emission regulations may require the use of a fully integrated system of the type shown in Figure 2. Only through the development of bidirectional linkages between all three system components can environmental issues be adequately assessed.

\section{AN APFLICATION OF AN INTEGRATED MODELINC ATPROACH} 'IO SYNTHETIC FUELS POLICY

Recent events in Iran and actions by OPEC have again demonstrated that heavy U.S. reliance on imported oil involves considerable risks both to national security and to the economy. The problems have been compounded by heightened concern over the safety of nuclear power. These developments have led to renewed concern over current energy policy and have provider an opportunily to detine and clarify its direction. In the process of review it is important to compare and evaluate alternativc policy strategies. This section presents a surmary of a larger study which reviewed several energy policy options. 2 
Specifically, this study describes two possible strategies and analyzes each in terms of its economic, environmental, and national security benefits and costs. The first introduces no new policies beyond those already in effect, while the second focuses on the acceleration of domestic supply expansion. Each strategy is represented by a specific policy. The first strategy is to retain the status quo, and to simply continue those programs and policies currently enacted or announced, and under direct control of the Executive Branch (e.g., the oil import quota). The second strategy is analyzed in terms of the synthetic fuels development program proposed by President Carter on July 15, 1979.

These policy alternatives are analyzed over the period 1980-2000 in terms of their effects on the economy, the environment, and national security (indicated by reliance on imports). The analytical framework used for these assessments is the TESOM-LITM system of Brookhaven National Laboratory and Dale $W$. Jorgenson Associates. This framework provides an integrated view of the energy, economic, and environmental systems, fully incorporating the static and dynamic interactions between energy and the economy. The method of analysis is first to project developments under the no new policy strategy, and then to make an alternative projection corresponding to the mure active policy stance.

The principal quantitative results of the policy comparison are summarized in the benefit and cost measures in the accompanying table. The level of U.S. oil imports is an indicator of the degree of attainment of energy security objectives; real GNP is an indicator of economic performance; coal and uranium usage is an indicator of environmental and health effects.

Each energy strategy reduces U.S. dependence on foreign petroleum. At present, about $8 \mathrm{million}$ barrels a day (mbd) of oil are imported; the continuation of present policies (specifically, the oil import quota) reduces this to about 4 mmbd by 1990 , and the synfuels policy achieves still greater reductions. For the longer term, to 2000 , present policy holds imports to about $4 \mathrm{mmbd}$, but the synfuels program reduces them to

Table 1

Summary of Energy, Economy, and Environmental Efferts of Energy Policies

\begin{tabular}{llrr}
\hline Year & \multicolumn{1}{c}{$\begin{array}{c}\text { Benefit/cost } \\
\text { indicator }\end{array}$} & $\begin{array}{r}\text { No new } \\
\text { policy }\end{array}$ & $\begin{array}{r}\text { Synfuels } \\
\text { policy }\end{array}$ \\
\hline 1990 & Oil imports, $10^{6}$ bbl/day & 4.3 & 2.8 \\
& Real GNP, $10^{9} \$(1972)$ & 1901 & 1889 \\
& Coal and uranium use, $10^{15}$ Btu/yr & 39 & 43 \\
2000 & Oil imports & 4.0 & 0.7 \\
& Real GNP & 2469 & 2413 \\
& Coal and uranium use & 54 & 61 \\
\hline
\end{tabular}


under 1 mmbd. Thus, in terms of security objectives, each energy strategy makes a positive contribution, with synfuels clearly more effective than the status quo. Another energy objective is to limit total U.S. energy consumption. With continuation of present policy, the growth of primary energy consumption is slowed to under 2.0 percent per annum-considerably lower than the overall rate of economic growth. Under the synfuels policy, energy growth is somewhat more rapid because of the conversion losses associated with the production of synthetic fuels.

Economic growth is projected to continue under each of the two strategies. (Amounts given below are in 1972 dollars.) In the no new policy case, real GNP growth averages 2.8 percent per annum to 2000 . The synfuels policy results in economic costs: real GNP is below the level of the reference case by $\$ 12.4$ billion in 1990 and by $\$ 56.0$ billion in 2000 .

The direction and magnitude of the changes in values of environmental and health measures across the policies are governed largely by the changes in the levels of coal and uranium utilization. All the environmental effects assessed (air and waterborne emissions, person-days lost because of occupational hazards, and population exposure to nuclear radiation) change in the same direction as coal and uranium use. The synfuels policy generates air and water emissions and occupational and safety hazards greater than those of the reference case because these depend predominately on coal usage, which is higher in the synfuels case. Uranium usage is unchanged from the reference to the synfuels case, and therefore population exposure to radiation is the same. Thus, even though specific conclusions concerning the environmental and health impacts of these energy policies cannot be ascertained without information concerning the location of the emitters and the population, it is clear that the synfuels policy will have greater environmental and health effects than the continuation of current policies.

These analytical results have important implications for the design and direction of U.S. energy policy. The results should not be interpreted as denying the potential benefits from synfuels programs. The introduction of synfuel technologies at the levels and rates assumed in this analysis secures these benefits only at the risk of significant economic and environmental costs. For synfuel technologies, therefore, programs directed toward cost reduction, performance enhancement, and resolution of environmental problems related to coal extraction and conversion appear preferable to those promoting accelerated commercial deployment.

\section{VIII.1 Study Assumption and Methods}

General Approach. Each of the strategies is analyzed by developing an integrated projection of the nation's energy and economic systems. The projection measures the energy, economic, and environmental impacts associated with the implementation of a set of energy polisies. Each projection is nhtained by applying an integrated energy-economy model (described in the next section) to the estimation of the structure and growth of the U.S, energy and economic sysrems. 
The reference projection, representing the first strategy, is developed on the premise that only those policies currently enacted or announced and under direct control of the Executive Branch are in effect. The second strategy is developed from the reference projection by assuming implementation of the President's synthetic fuels program as proposed in his speech of July 15, 1979.

Modeling Approach. The modeling approach used in this study employs an integrated set of technological and economic models to explore the national energy and economy responses to proposed energy policies. The integrated system is composed of three component models: an aggregate structural model of economic growth, a comprehensive energy system model, and a detailed input-output model for the U.S. economy. This system of models has been integrated to provide a comprehensive long-run representation of the U.S. energy and economic systems and energy-economy interactions. 7,8

The economic growth model is the Dale W. Jorgenson Associates (DJA) Long-term Interindustry Transactions Mndel (LITM). 9 LITM provides a flexible interindustry representation of sectoral production and final demand, and captures the combined influences of productivity, investment, and labor supply on the expansion of U.S. productive capacity over the long run. The detailed technological model of energy supply, conversion, and end-use demand is the Time-stepped Energy System Optimization Model (TESOM) developed at Brookhaven National Laboratory. 10 TESOM represents the range of feasible energy resource and technology substitutions for the U.S. energy system. It is formulated as a mathematical progranming model to optimize the mix of supply, conversion, and demand technologies to meet a set of energy service demands. TESOM is stepped through time to capture the dynamics of energy prices, technology development, and service demand. The input-output model is that developed jointly.by Brookhaven National Laboratory and the University of Illinois.11 This detailed input-output model is used to transform the sectoral output and consumption levels modeled in LITM into a restructured set of demands for energy services in physical units.

Figure 5 is a representation of the integrated modeling structure indicating the flow of information among the cumponent models. Solutions to the system of models for any given set of analytical assumptions are found through a process of iteration and adjustment, until consistency among model components is obtained. The iterative process is carried out for each year in the study, with 'the solution moving sequentially forward sver the years involved.

\section{VIII.2 Reference Case Assumption}

Economic Assumptions. The LITM economic model requires input assumptions on future population, government expenditure and revenue policies, and unemployment ratc. The Census Bureau's Series II population projections (fertility rate of 2.1) were used to derive figures win the future population. Labor force participation rates are endogenous to the model and are not specified as assumptions. The unemployment rate is assumed to follow a cyclical rate, from 6.0 percent in 1978 to 5.6 percent in 1985, and then to decline slightly over the rest of the forecast period. A slight increase in government purchases relative to the rest 

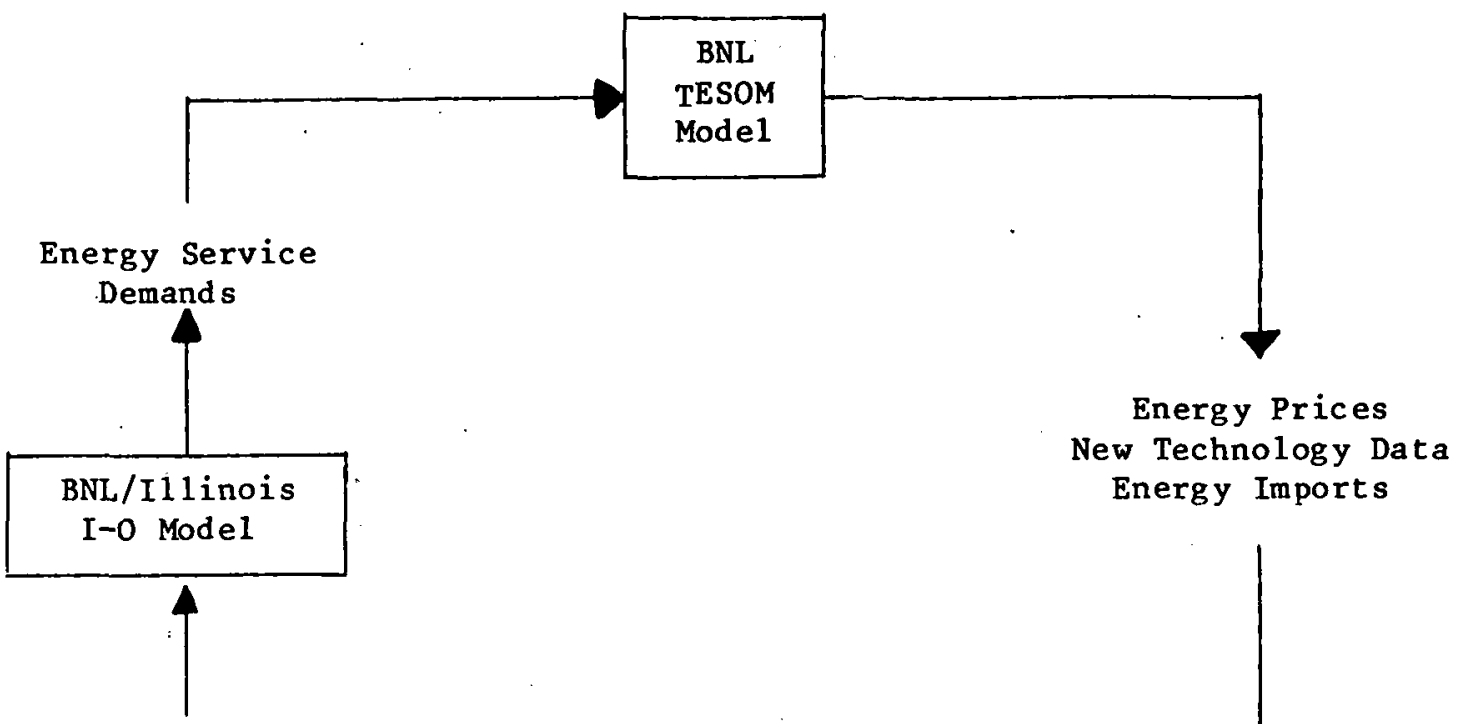

Energy Demands Economic Conditions

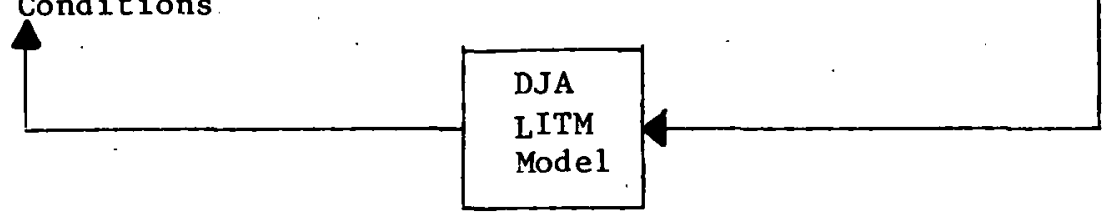

Figure 5. Integrated model structure.

of the economy (from 19.4 percent of real GNP in 1980 to 19.9 percent by 2000) is assumed, reflecting current trends of government programs including new developments in the health, services, energy, and defense areas. Government transfers and tax revenues are assumed to rise approximately in line with the econorny as a whole. Most of the productivity effects in the model are endogenous and are not specified as assumptions, and the energy supply and productivity information is obtained from the TESOM model.

Energy Assumptions. The reference case projection incorporates a variety of energy system assumptions: prices and availabilities of energy resources; capital and opcrating costs for electricity generation, synthetic fuel production, and end-use devices; limits on the market penetration rates for new energy technologies; and changes in efficiencies of fuel conversion over the 1980 to 2000 time horizon. The energy assumptions include the impacts of policy initiatives or actions already legislated or announced and under control of the Executive Branch. In particular, the reference case incorporates the oil import quotas announced by President Carter in his energy initiatives speech of July 15, 1979. These quotas require that future annual levels of oil imports never exceed the 1977 level, and that they be reduced to one-half that level by 1990 . 
Domestic pricing assumptions are based on the phased decontrol of domestic oil prices by 1981. A windfall profits tax (proposed but not enacted) is not included. The U.S. Department of Energy NEP II High Price Trajectory is assumed for world oil prices, 12 in which the world oil price rises at an average annual rate of 3.3 percent from $\$ 20$ per barrel in 1980 to $\$ 38$ by 2000 (in constant 1978 dollars). Domestic natural gas prices are assumed to be deregulated by 1985 and then to rise rapidly until they approach the crude oil price, from $\$ 1.18$ per million Btu in 1980 to $\$ 6.58$ by 2000 (1978 dollars).

Domestic oil and gas production possibilities are determined by applying a Hubbert curve analysis to the U.S.G.S. mean geology estimates. 13 Nuclear electric generating capacity is assumed to reach 155 gigawatts during the 1985 to 1990 period and to increase to 215 gigawatts by 2000 .

Environmental Assumptions. A set of measures of environmental effects is generated frum each TESOM solution by using emission and conversion factors associated with specific technologies. The impacte measured include air- and waterborne emissions, land use, occupational injuries, and $i$ tems such as radiation exposure levels. The emission and conversion factors are based on the assumption that best currently available control technologies are used in each process in the system, but their effectiveness does not change over time.

\section{VIII.3 Energy Assumptions - Synfuels Case}

The synfuels program is modeled to conform to President Carter's synthetic fuel proposal of July 15, 1979, which called for an incremental production goal of 2.5 million barrels per/day (crude oil equivalent) of synthetic fuels by 1990 . The assumed allocation of this increment is given in Table 2.

Synthetic fuel production is assumed to continue to increase during the post-1990 period at an annual rate of 10 percent, a somewhat more moderate increase than in the reference projection (but from a significantly higher 1990 base). The synfuels cost assumptions are given in Table 3 .

\section{VIII.4 Comparison of Reference and Bynfuels Policy}

Tables 4, 5, and 6 show the relationships between the reference and synfuels projections.

Table 2

Synthetic Fuel Increments

\begin{tabular}{lc}
\hline & Milion bbl/day \\
\hline Coal liquids* & 1.25 \\
Hi-Btu coal gas & 0.25 \\
Shale oil & 0.40 \\
Biomass gas & 0.10 \\
Unconventional gas & 0.50 \\
$\quad$ Total & 2.50
\end{tabular}


Table 3

Synthetic Fuel Cost Assumptions*

\begin{tabular}{|c|c|c|c|}
\hline & \multicolumn{3}{|c|}{$1975 \$ / 10^{6} \mathrm{Btu}$} \\
\hline & 1980 & 1990 & 2000 \\
\hline $\begin{array}{l}\text { Coal liquids } \\
\text { Coal methanol } \\
\text { Hi-Btu coal gas } \\
\text { Shale oil } \\
\text { Biomass gasification } \\
\text { Unconventional gas }\end{array}$ & $\begin{array}{l}3.05 \\
3.61 \\
2.52 \\
3.62 \\
2.96 \\
3.26\end{array}$ & $\begin{array}{l}3.33 \\
3.89 \\
2.80 \\
4.99 \\
3.47 \\
5.04\end{array}$ & $\begin{array}{l}3.69 \\
4.25 \\
3.16 \\
6.89 \\
4.42 \\
6.88\end{array}$ \\
\hline $\begin{array}{l}\text { * Costs are equal to the sum of } \\
\text { maintenance, and fuel cost. }\end{array}$ & annualized & capital cost, operating & and \\
\hline
\end{tabular}

Table 4

Comparison of Cases,

Economic Sumary in $10^{9} \$(1972)$

\begin{tabular}{llccc}
\hline & & & Difference & $\%$ Change \\
\hline & Reference case & $\frac{\text { Synfuels }}{1888.9}$ & -12.4 & -0.65 \\
1990 GNP & 1901.3 & 2413.3 & -56.0 & -2.20 \\
\hline
\end{tabular}

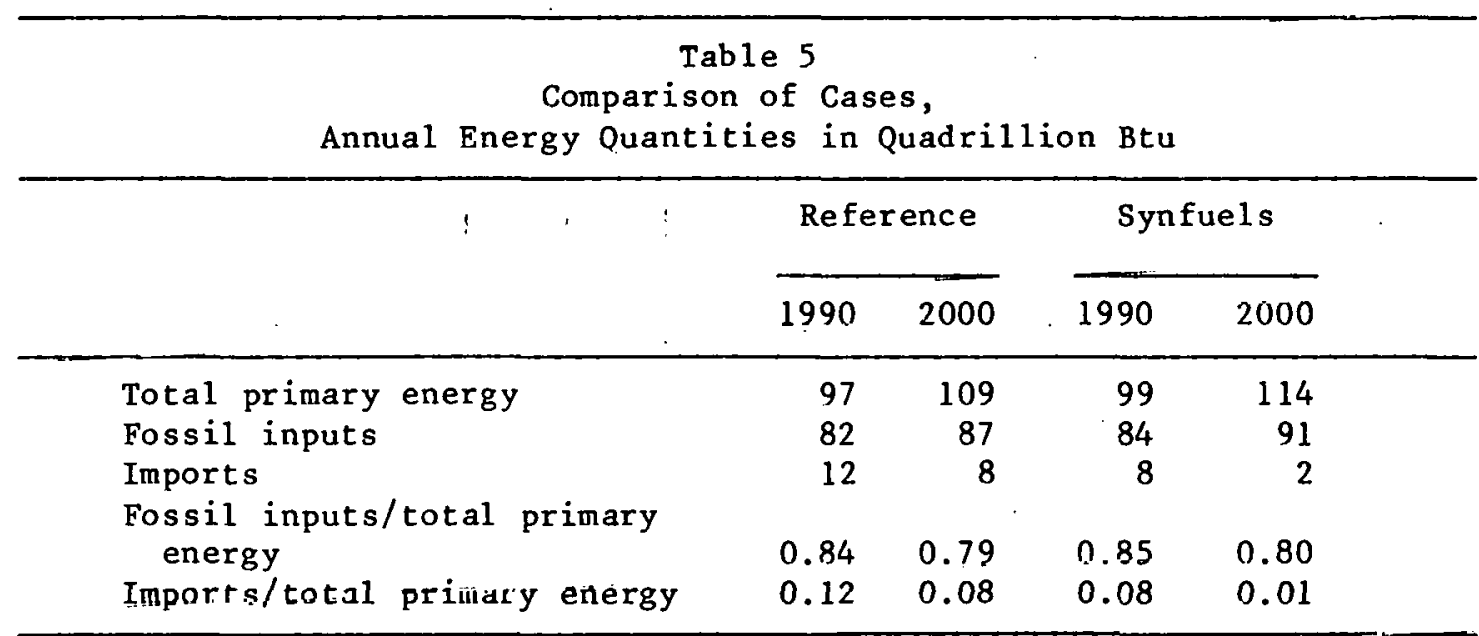

*Coal liquids production includes methanol and coal liquefaction output. 
Table 6

Comparison of Cases,

Environmental Measures

\begin{tabular}{|c|c|c|c|c|}
\hline & \multicolumn{2}{|c|}{ Reference } & \multicolumn{2}{|c|}{ Syn fuels } \\
\hline & 1990 & 2000 & 1990 & 2000 \\
\hline $\begin{array}{l}\text { Airborne emissions, } 10^{6} \text { tons } \\
\text { Waterborne emissions, } 10^{6} \text { tons } \\
\text { Person-days lost, } 10^{3} \\
\text { Population exposure, } \\
\quad 10^{6} \text { man-rem/yr }\end{array}$ & $\begin{array}{r}34.5 \\
1.9 \\
667.0 \\
0.7\end{array}$ & $\begin{array}{r}39.5 \\
2.3 \\
903.8\end{array}$ & $\begin{array}{r}38.1 \\
2.0 \\
725.5\end{array}$ & $\begin{array}{r}46.4 \\
2.7 \\
1122.7\end{array}$ \\
\hline
\end{tabular}

The synfuels policy, compared with the reference case, succeeds in reducing U.S. dependence on imports. Synthetic fuels displace 35 percent ( 4.2 quads) of U.S. annual import requirements in 1990 and 80 percent ( 6.7 quads) in 2000. The policy does not reduce aggregate energy consumption; in fact, because of the above-average conversion losses in synfuels production, aggregate annual energy consumption is higher than in the reference case by 2 quads in 1990 and 5 quads in 2000. However, this increased consumption is supplied entirely from domestic resources (coal).

The synfuels policy imposes a small net economic cost on the economy: real GNP is lower than in the reference case, by 0.7 percent $(12.4$ billion 1972 dollars) in 1990 and 2.2 percent (56.0 billion.1972 dollars) in 2000. Thus, in all years, real output and incomes are reduced somewhat by the synfuels measures, and the rate of economic growth is slowed. In terms of the inputs to the production of aggregate output, the synfuels policy results in an economy that is more capital, labor, and energy intensive than in the reference case and less intensive in the use of intermediate materials. This results in somewhat higher employtment, but also in slightly lower productivity of labor and capital, so that the rate of growth of production and real income shows an ovcrall decline. Levels of environmental measures arc higher with the synfuels policy than in the reference projection.

\section{1.5 Puliey Implications}

The results of this analysis yicld important implications for the fucus and dirertion of U.S. energy policy. Both of the strategies considered succeed in reducing dependence on iuports and slowing the growth in energy demand. In the reference projection, import quotas and domestic oil and gas price decontrol reduce oil imports to half their current levels, and also lower the annual growth of primary energy consumption and shift energy use patterns toward greater utilization of coal. The synfuels policy further reduces U.S. import requirements. The large-scale introduction of synthetic fuels results in only marginally higher primary energy consumption than in the reference case. Thus, to different degrees, a slowing of the growth in energy use is evident under both strategies. 
These conclusions should not be interpreted as advocating de-emphasis of supply expansion. The less favorable economics of the synfuels policy are directly attributable to the costs of the policy. A synfuels program aimed at reducing the cost of synthetic fuel production has the potential for mitigating the negative economic aspects of a program focusing on accelerated commercial deployment of current technologies.

In developing the synfuels projection, the capital and labor costs for each synfuel technology were assumed to be invariant over time, without regard to cost reductions due to learning effects, technical improvement, economies of scale, or other means of productivity enhancement. Cost reductions for the synthetic and unconventional fuels technologies can dramatically reduce the net economic cost associated with this policy. Lowering the costs of such fuels reduces the adverse macroeconomic impact from the synfuels policy.

The major policy conclusion which emerges is that the premature, large-scale introduction of costly existing synthetic fuel conversion technologies results in reduced energy imports, but at the cost of lower economic growth and undesirable environmental effects. A research, development, and demonstration program aimed at reducing the costs of synfuel supply and lowering the environmental impacts of coal and shale extraction and conversion could reduce or eliminate the negative economic and environmental aspects of the synfuels policy analyzed here.

\section{CONCLUSION}

This report has focused upon conceptual issues associated with integrated energy policy analysis. Much of the paper is presented in modeling terms since a comprehensive systematic analysis of policy is often carried out through use of mathematical modeling techniques. One must recognize that mathematical modeling requires a degree of problem idealization to put policy issues into tractable form. Model results will, therefore, provide information about behavior of idealized systems, and a decisionmaker must use this information to make decisions for the nonidealized problem.

Secondary impacts of energy or environmental policies can only be assessed in a fully integrated framework, but many of these impacts are poor$1 y$ understood and extremely difficult to model. Individuals or groups of individuals respond to their perceptions of costs and benefits, health risks, or potential environmental impacts rather than to perfect information concerning these effects.

Use of idealized problem formulations is necessary in technology assessment particularly in considering highly integrated policy issues, such as a synfuels policy. Nonquantifiable factors, such as equity, are not always considered in mathematical models. Model results should therefore be viewed as aids for decisionmaking among policy alternatives, as they may not consider all aspects of the policy's implications. A decisionmaker must recognize the limitations on use of model outputs and must use both experience and judgment in selecting policy alternatives for implementation. Higher levels of model detail are not always uecessary for improving policy assessment capability. Use of an appropriate model structure with sufficient feedback capabilities will often provide a better overall policy assessment than use of a highly detailed but uncoordinated approach to the same problem. 
1. Kleeman, P.T., Lukachinski, J., and Groncki, P.J., Methodologies for Integrated Environmental Impact Analysis, BNL Forthcoming, 1979.

2. Davitian, H., Groncki, P.J., Kleeman, P., Lukachinski, J., Goettle, R.J. and Hudson, E.A., A Strategic Cost-Benefit Analysis of Energy Policies: Overview, BNL 51105, October 1979

3. Hoffman, K.C., Beller, M., Cherniavsky, E.A., and Fisher, M., "Multi-objective Analysis of ERDA Combined Technology Scenarios." BNL 21091 , September 1976.

4. Cherniavsky, E.A., Kydes, A.S., Davidoff, J.W., "Multi-objective Function Analysis of ERDA Forecast-2, Year 2000 Scenario." BNL 50685, May 1977.

5. Zionts and Wallenius, "An interactive programming method for solving the multiple criteria problem." Management Sci. 22, 652-663, 1976.

6. Schank, J.D., "An Alternative Semi-automated Method for Performing Mul.ti-objective Analyses." BNL 50892, August 1978.

7. Groncki, P.J. and Marcuse, W., The Brookhaven Integrated Energy/ Economy Modeling System and Its Uses in Conservation and Policy Analysis, BNL 51056, 1979.

8. Lukachinski, J., Groncki, P.J. Tessmer, R.G., Goet.tle, R.J., and Hudson, E.A., An Integrated Methodology for Assessing Energy-Economy Interactions, BNL 26452, 1979.

9. Hudson, E.A. and Jorgenson, D.W., The Long-Term Interindustry Transactions Model: A Simulation Model for Energy and Economic Analysis, Final Report to the Applied Economics Division, Federal Preparedness Agency, General Services Administration, 1977.

10. Kydes, A.S., The Brookhaven Energy Gyatem Optimization Mode1: Its Variants and Uses, BNL 50873, 1978.

11. Fraser, J.T., Documentation of the Brookhaven Energy I-0 and I-O/ BESOM Linkage, BNL 50856, 1978.

12. National Energy Plan II, U.S. Department of Ënergy, Washingrou, DC, May 1979.

13. Annual Report to Congress 1978, Vol. 3, DOE/EIA-0173/3, Washington, טC. 